\title{
Performance of an Annular Linear Induction Pump with Applications to Space Nuclear Power Systems
}

\author{
Kurt A. Polzin*, Michael Schoenfeld, J. Boise Pearson, Kenneth Webster, Thomas Godfroy ${ }^{\dagger}$ \\ NASA-Marshall Space Flight Center, Huntsville, AL 35812 \\ Harold E. Adkins, Jr. \\ Pacific Northwest National Laboratory, Richland, WA 99352 \\ James E. Werner \\ Idaho National Laboratory, Idaho Falls, ID 83415
}

\begin{abstract}
The Early Flight Fission - Test Facility (EFF-TF) was established by the Marshall Space Flight Center to provide a capability for performing hardware-directed activities to support multiple in-space nuclear reactor concepts by using a non-nuclear test methodology. [1,2] This includes fabrication and testing at both the module/component level and near prototypic reactor configurations. The EFF-TF is currently supporting an effort to develop an affordable fission surface power (AFSP) system that could be deployed on the Lunar surface. [3] The AFSP system is presently based on a pumped liquid metal-cooled (Sodium-Potassium eutectic, NaK-78) reactor design. [4,5] This design was derived from the only fission system that the United States has deployed for space operation, the Systems for Nuclear Auxiliary Power (SNAP) 10A reactor, which was launched in 1965. [6]

An important component for this system is the pump that drives the liquid metal through the system. In the present AFSP system, that pump is an annular linear induction pump (ALIP). The pump duct has no moving parts and no direct electrical connections to the liquid metal containing components. Pressure is developed by the interaction of the magnetic field produced by the stator and the current which flows as a result of the voltage induced in the liquid metal contained in the pump duct. Flow may be controlled by variation of the voltage supplied to the pump windings. Three-phase power is provided to the pump through an electrical power system that uses pulse-width modulation to produce current waveforms at an arbitrary frequency, with the overall phase-to-phase voltage on the pump set by a variac on the modulated output of the power system.
\end{abstract}

A NaK flow loop (see Fig. 1) has been fabricated to allow for testing of this pump and others like it, allowing for the development of pump performance curves over a variety of flow conditions. The loop consists of the ALIP, a variable throttling orifice, a flow meter, an induction heater, and a NaK-to-gas heat exchanger. The temperature is varied using the heater and heat exchanger, and the flow is controlled by adjusting the amount of power provided to the pump and the flow restriction introduced by the throttling orifice.

Under steady-state conditions, pump performance is measured for flow rates from $0.5-4.3 \mathrm{~kg} / \mathrm{s}$. The pressure rise developed by the pump to support these flow rates is roughly $5-65 \mathrm{kPa}$. The RMS input voltage (phase-to-phase voltage) ranges from $5-120 \mathrm{~V}$, while the frequency can be varied arbitrarily up to $60 \mathrm{~Hz}$. Performance is quantified at different loop temperature levels from $50 \mathrm{C}$ up to $650 \mathrm{C}$, which is the peak operating temperature of the proposed AFSP reactor. The transient response of the pump is also evaluated to determine its behavior during startup and shut-down procedures.

\footnotetext{
* Propulsion Research Engineer, Propulsion Research and Technology Applications Branch, Propulsion Systems Department. Senior Member AIAA.

${ }^{\dagger}$ Maximum Technology Corporation, Huntsville, AL, 35814.
}

1 of 2 


\section{REFERENCES}

[1] T.J. Godfroy, M. Van Dyke, and R. Dickens, "Realistic Development and Testing of Fission Systems at a NonNuclear Testing Facility," Space Technologies and Applications International Forum (STAIF-2000), AIP, 504:1208 (2000).

[2] M. Van Dyke, T.J. Godfroy, M. Houts, et al., "Results of a First Generation Least Expensive Approach to Fission Module Tests: Non-Nuclear Testing of a Fission System," Space Technologies and Applications International Forum (STAIF-2000), AIP, 504:1211 (2000).

[3] M. Houts, S. Gaddis, R. Porter, et al., "Options for Affordable Fission Surface Power Systems," Proceedings of the 2006 International Congress on Advances in Power Plants (ICAPP), ANS, paper 6370 (2006).

[4] D.D. Dixon, M. Hiatt, D.I. Poston, et al., "Design of a 25-kWe Surface Reactor System Based on SNAP Reactor Technologies," Space Technology and Applications International Forum (STAIF-2006), AIP, 813:932 (2006).

[5] D.I. Poston, R.J. Kapernick, D.D. Dixon, et al., "Reference Reactor Module for the Affordable Fission Surface Power System," Space Technology and Applications International Forum (STAIF-2008), AIP, 969:277 (2008).

[6] J.A. Angelo and D. Buden, Space Nuclear Power, Orbit Book Company, Malabar, FL (1985).

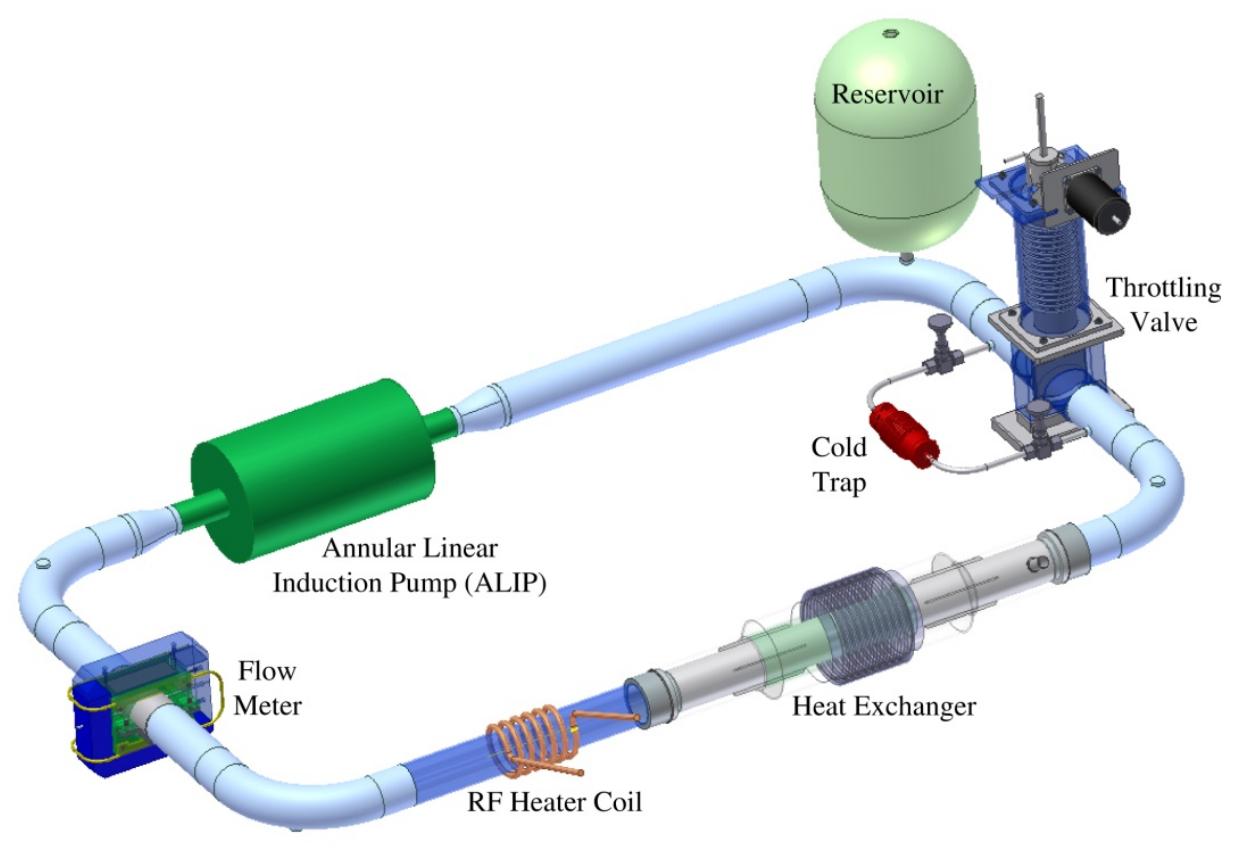

Fig. 1: Rendering showing the components in the flow loop. NaK flow through the loop is clockwise. 


\title{
Performance of an Annular Linear Induction Pump with Applications to Space Nuclear Power Systems
}

\author{
Kurt A. Polzin*, Michael Schoenfeld, J. Boise Pearson, \\ Kenneth Webster, Thomas Godfroy $\dagger^{\dagger}$ and John Bossard ${ }^{\ddagger}$ \\ NASA-Marshall Space Flight Center, Huntsville, AL 35812 \\ Harold E. Adkins, Jr. \\ Pacific Northwest National Laboratory, Richland, WA 99352 \\ James E. Werner \\ Idaho National Laboratory, Idaho Falls, ID 83415
}

\begin{abstract}
Results of performance testing of an annular linear induction pump are presented. The pump electromagnetically pumps liquid metal through a circuit specially designed to allow for quantification of the performance. Testing was conducted over a range of conditions, including frequencies of 33, 36, 39, and $60 \mathrm{~Hz}$, liquid metal temperatures from 125 to $525{ }^{\circ} \mathrm{C}$, and input voltages from 5 to $120 \mathrm{~V}$. Pump performance spanned a range of flow rates from roughly 0.16 to $5.7 \mathrm{~L} / \mathrm{s}(2.5$ to $90 \mathrm{gpm})$, and pressure head $<1$ to $90 \mathrm{kPa}(<0.145$ to $13 \mathrm{psi})$. The maximum efficiency measured during testing was slightly greater than $6 \%$. The efficiency was fairly insensitive to input frequency from 33 to $39 \mathrm{~Hz}$, and was markedly lower at $60 \mathrm{~Hz}$. In addition, the efficiency decreased as the NaK temperature was raised. The performance of the pump operating on a variable frequency drive providing $60 \mathrm{~Hz}$ power compared favorably with the same pump operating on $60 \mathrm{~Hz}$ power drawn directly from the electrical grid.
\end{abstract}

\section{Nomenclature}

$B_{r} \quad$ radial magnetic field, $\mathrm{T}$

$B_{z} \quad$ axial magnetic field, $\mathrm{T}$

b calibration constant, $\mathrm{L} / \mathrm{s}$

m calibration constant, $(\mathrm{L} / \mathrm{s}) / \mathrm{mV}$

$P_{\mathrm{IN}} \quad$ pump input power, $\mathrm{W}$

$\begin{array}{ll}\Delta p & \text { change in pressure, } \mathrm{Pa} \\ V & \text { signal voltage, } \mathrm{V} \\ \dot{v} & \text { volumetric flow rate, } \mathrm{L} / \mathrm{s} \\ \eta & \text { efficiency, } \%\end{array}$

\section{Introduction}

$\mathrm{F}$ ISSION surface power (FSP) systems could be used to provide power on the surface of the Moon, Mars, or other planets and moons of our solar system. Fission power systems could provide excellent performance at any location, including those near the poles or other permanently shaded regions, and offer the capability to provide on-demand power at any time, even at long distances from the Sun. Fission-based systems also offer the potential for outposts, crew, and science instruments to operate in a power-rich environment.

Under the NASA Exploration Technology Development program, NASA and the Department of Energy have begun long-lead technology development for potentially supporting future integrated FSP systems. The major effort in the FSP technology project has been focused on a reference mission and concept. The reference mission is to provide $40 \mathrm{~kW}_{\mathrm{e}}$ power to habitats on the lunar surface over a design life of 8 years. Although many options exist, NASA's

${ }^{*}$ Propulsion Research Engineer, Propulsion Research and Technology Applications Branch, Propulsion Systems Department. Senior Member AIAA.

${ }^{\dagger}$ Maximum Technology Corporation, Huntsville, AL.

${ }^{\ddagger}$ BSRD, LLC/Yetispace, Inc., Huntsville, AL. 
current reference FSP system uses a fast spectrum, pumped liquid, sodium-potassium- (NaK-) cooled reactor coupled to a Stirling power conversion subsystem. An annular linear induction pump (ALIP) is used to pump the liquid-metal coolant in the system. The reference system uses technology with significant terrestrial heritage that can perform at any location on the surface of the Moon or Mars. Detailed development of the FSP concept and the reference mission are documented in various other reports. ${ }^{1-4}$

The Early Flight Fission-Test Facility was established by MSFC to provide a capability for performing hardwaredirected activities to support multiple in-space nuclear reactor concepts by using a nonnuclear test methodology. 5,6 This includes fabrication and testing at both the module/component level and near prototypic reactor components and configurations, allowing for realistic thermal-hydraulic evaluations of systems.

The reference FSP system uses an ALIP because it can operate at moderate to elevated temperatures for extended periods of time and it is typically one of the more efficient inductive electromagnetic molten metal conveyance technologies. Electromagnetic pumps do not contain moving parts that can mechanically wear over the lifetime of the reactor system. Consequently, these pumps require no bearings, seals or associated maintenance. Futhermore, unlike DC electromagnetic pumps that experience higher Ohmic losses in the power lines due to the required combination of high-current/low-voltage power, an ALIP draws 3-phase AC power at moderate and manageable currents and voltages.

In the present testing, the ALIP test circuit (ATC) was fabricated to provide the capability to measure the performance of induction pumps over a wide range of input conditions and environments. The system is described in detail in section II, followed by measured performance results on the present ALIP. Greater detail on the system and testing can be found in a report by Polzin $e t$ al. ${ }^{7}$

\section{Experimental Apparatus and Test Setup}

The ATC apparatus, shown schematically and photographically in Fig. 1, was fabricated to allow for performance testing of liquid-metal induction pumps. The present test circuit consists of the ALIP, an induction heater, a throttling valve, an electromagnetic flowmeter, and a gaseous nitrogen- $\left(\mathrm{GN}_{2}-\right)$ to-NaK heat exchanger. A large pipe size (3-in, schedule 10, stainless steel) was employed to minimize the viscous flow losses throughout the loop. A description of the major hardware and instrumentation components of the system is presented in the remainder of this section.

\section{A. Annular Linear Induction Pump}

The design and development of the ALIP was performed by Idaho National Laboratory (INL) and is discussed in a companion report. ${ }^{8}$ Three-phase power is applied to the pump to produce an axially-traveling magnetic wave. This magnetic wave induces currents in the liquid metal, which subsequently interact with the magnetic field to produce a Lorentz body force on the fluid, pushing it through the system.

In the present experiment, an Allen Bradley PowerFlex 400 variable frequency drive (VFD) with a sine wave filter was employed to set the frequency of the power delivered to the pump to an arbitrary value from zero to $60 \mathrm{~Hz}$. The VFD employs pulse width modulation (using a 4-kHz carrier wave frequency) to produce an approximately sinusoidal current at these arbitrary frequency levels. The filtered VFD output was passed through a variac transformer to control the voltage. By adjusting the variac, the voltage and commensurate power to the pump could be controlled to an arbitrary level.

\section{B. Addtional Test Circuit Hardware}

An in-house custom designed valve was used to control the flow impedance in the system. A gate valve design was selected to produce the smallest pressure drop across the valve, making use of a welded bellows to provide actuation and hermetic sealing of the valve. The high-temperature $\mathrm{NaK}$ required stainless steel (SS) or similar materials for all wetted surfaces. The gate itself was constructed of Inconel $(\mathbb{R}$. This material was selected because it has a lower coefficient of thermal expansion than the SS grade 304 that comprised the rest of the valve body, and also to prevent galling between the valve body and the gate. The bellows was sized to provide 3 in of travel corresponding to the height of the duct. The valve was translated by a vacuum-rated motor that was connected through a worm-drive gearbox to the top plate of the bellows.

The NaK was heated using the radio frequency (RF) inductive heater coil shown in figure 8 . The coil was manufactured by Fluxtrol, Inc., Auburn Hills, MI, and was powered using a Toccotron 400, 12.5-kW, inductive heater power supply. Four graphite heaters were added to the ATC during testing to provide additional heat and allow for reaching the target maximum circuit temperature. The design involved clamping four tubes to the sides of the ATC pipe wall and sliding the heaters inside these tubes. A gas-to-NaK counterflow concentric tube heat exchanger was used to 


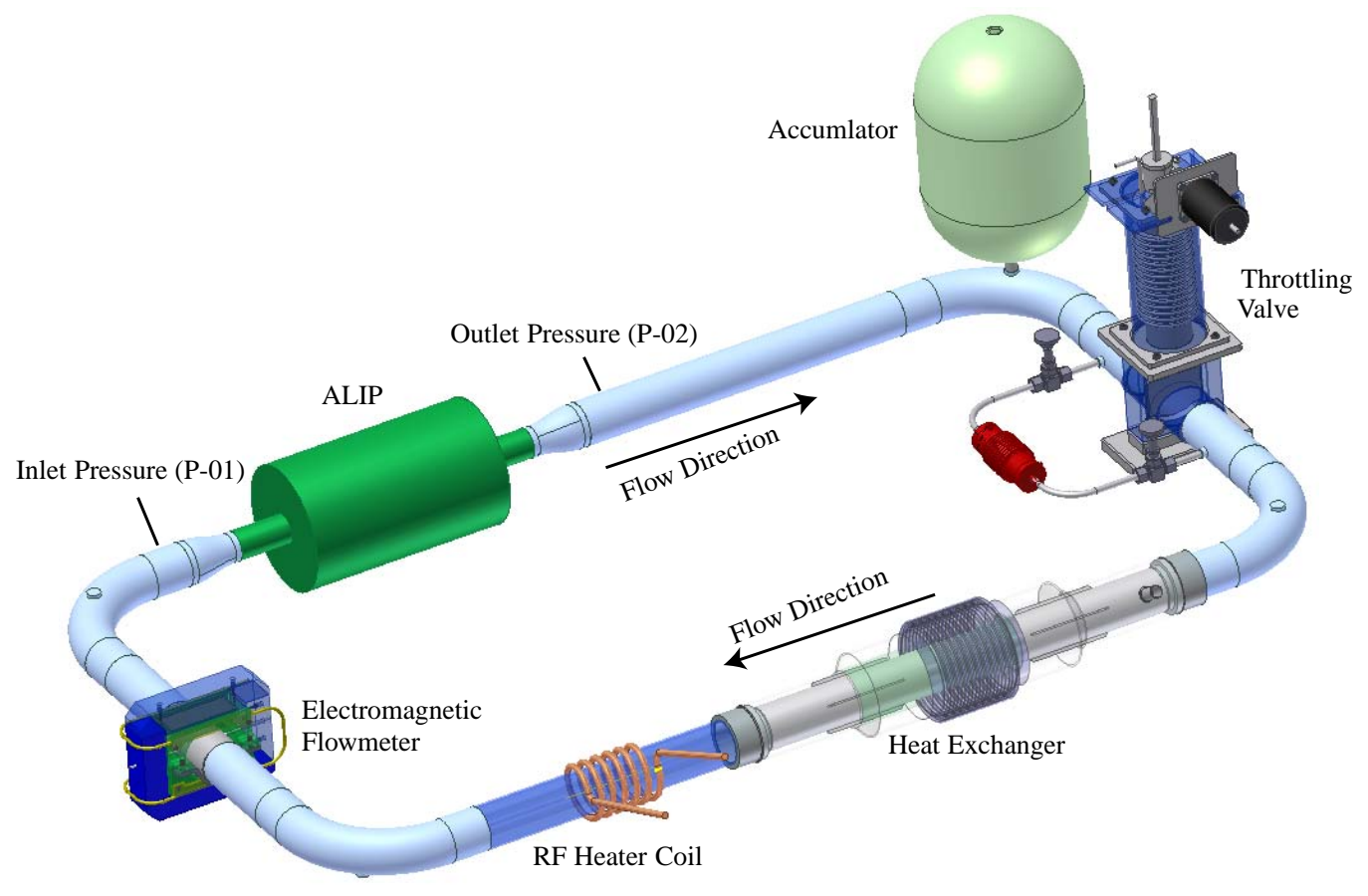

a)

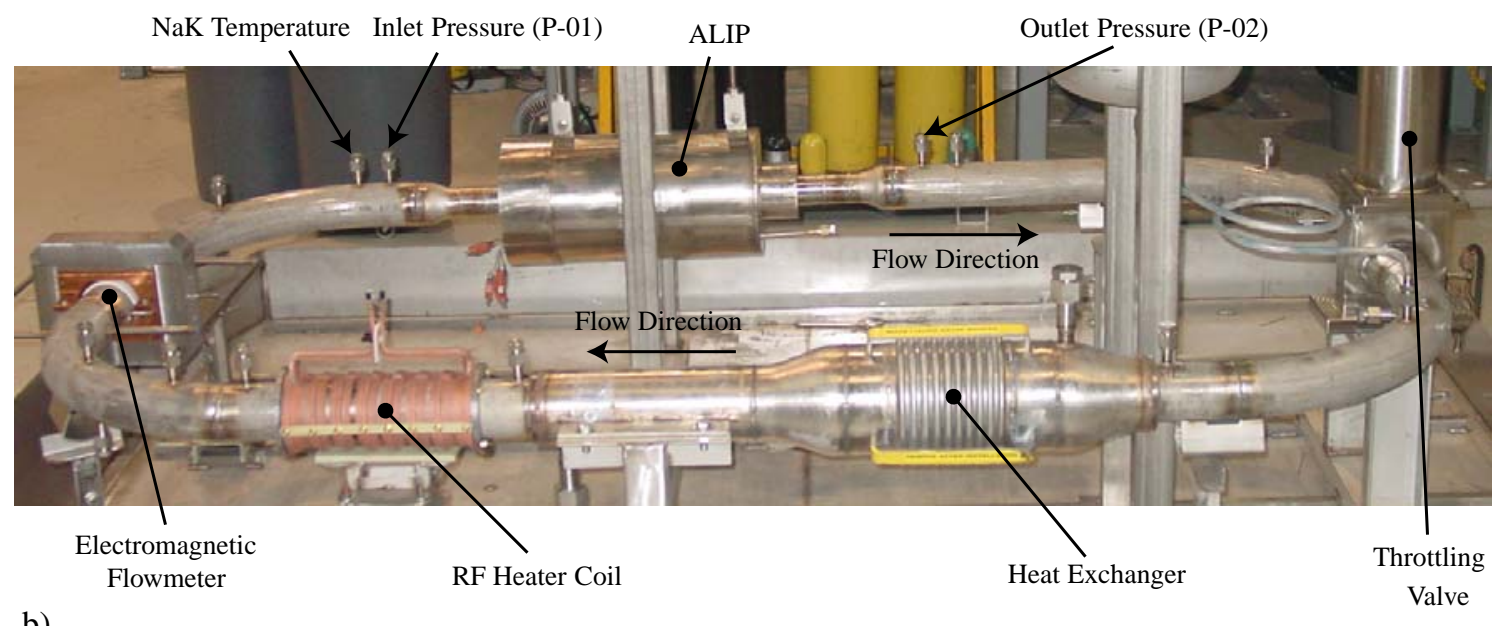

Figure 1. a) Schematic and b) photograph of the ALIP test circuit. 
provide cooling and temperature control for the loop. The heat exchanger was sized to provide $10 \mathrm{~kW}$ of cooling to the system using GN2 as the heat exchange medium.

\section{Instumentation}

The pressure transducers are manufactured by Delta Metrics, Worthington, OH. The transducer P-01 measures the absolute pressure of the NaK upstream of the ALIP, while the transducer P-02 performs the same measurement downstream of the ALIP. The differential pressure rise across the pump $\Delta p$ was taken as the difference between P-02 and P-01. A slight correction, explained in detail in Ref. [7] was developed to account for the pipe contraction after transducer P-01 and the expansion before transducer P-02.

An electromagnetic (EM) flowmeter was used to measure the volumetric flow rate of NaK in the system. It consisted of two neodymium-iron-boron magnets opposing each other on opposite sides of the pipe containing the flowing NaK. The magnetic flux return was provided using the magnetically permeable material Fluxtrol (Fluxtrol, Inc.). The volumetric flow rate $\dot{v}$ is linearly related to the induced voltage $V$ and can be written as

$$
\dot{v}=\mathrm{m} V+\mathrm{b}
$$

where the constant $\mathrm{m}$ is a function of the magnetic field strength and the geometry of the flow channel and $\mathrm{b}$ is an offset constant. Through calibration, the details of which are found in Ref. [7], the values of $m$ and $b$ were determined as $0.4063 \pm 0.0047(\mathrm{~L} / \mathrm{s}) / \mathrm{mV}$ and $0 \pm 0.0070 \mathrm{~L} / \mathrm{s}$, respectively.

The ALIP power was measured using an Ohio Semitronics two-meter wattmeter (model P-144D). The unit monitors the real three-phase power delivered to any load (connected in either a delta or a wye configuration) by simultaneously monitoring the current in two of the three legs and measuring the voltage in all three legs. ${ }^{9}$ The apparatus was calibrated to provide a data correction factor at low power that was dependent on the frequency of the three-phase power fed to the pump. This also significantly reduced the reported error on the power measurement.

\section{Pump Performance Measurements}

Presented in this section are performance measurements obtained during the course of testing. These data consist of volumetric flow rate $\dot{v}$, pressure rise across the pump $\Delta p$, input power $P_{\mathrm{IN}}$, and efficiency. Efficiency is equal to the fluid power divided by the input electrical power and is given as

$$
\eta=\frac{\dot{v} \Delta p}{P_{\mathrm{IN}}}
$$

Typically, data were acquired by first bringing the pump and loop temperature to a steady-state value. A constant pump voltage was then set using the variac. The throttling valve was exercised through its entire range to obtain pump performance curves over a range of $\dot{v}$ and $\Delta p$ values.

Before presenting the measured performance data, it is important to note that this pump encountered some issues during the fabrication process that could lead to a lower than expected efficiency. A few of the major issues are summarized as follows: The $\mathrm{Cu}$ coil windings were thicker than expected, so fewer coil turns were possible, leading to a magnetic field strength at a given applied current level that was lower than the design value. Also, there is an uncertainty in the magnetic properties of the stators and torpedo. This could be due to low cobalt content of the alloy or improper annealing, either of which could result in reduced magnetic field strength in the channel for a given applied power. As will be shown in the data, the currents supplied to each of the three phases were not equal. This may be due to a short circuit between coils, unbalanced mutual inductance between the different coils, or end effects causing the inductance of each leg to be slightly different. Consequently, while the efficiency of this pump is admittedly lower than was expected, these data should not necessarily be taken as representative of the best possible performance for an ALIP. These issues are detailed and addressed in a companion report. ${ }^{8}$

To demonstrate the remarkably clean nature of the test data, each individual data point over roughly 215 min of testing is plotted in Fig. 2a,b. These data were acquired at a sampling rate of $1 \mathrm{~Hz}$, a NaK temperature of $325{ }^{\circ} \mathrm{C}$, and an ALIP frequency of $36 \mathrm{~Hz}$. Each line of dots in panel (a) represents operation at a constant pump voltage. Concentrations of data points represent flow conditions measured at steady-state flow conditions while the throttling valve was stationary (roughly 40-60 s dwell time). The individual dots forming the rest of the lines represent data obtained while the valve was transitioning from one setpoint to the next. Each efficiency point was computed using the flow rate, $\Delta p$, and input power as measured and recorded on the data acquisition (DAQ) system. 


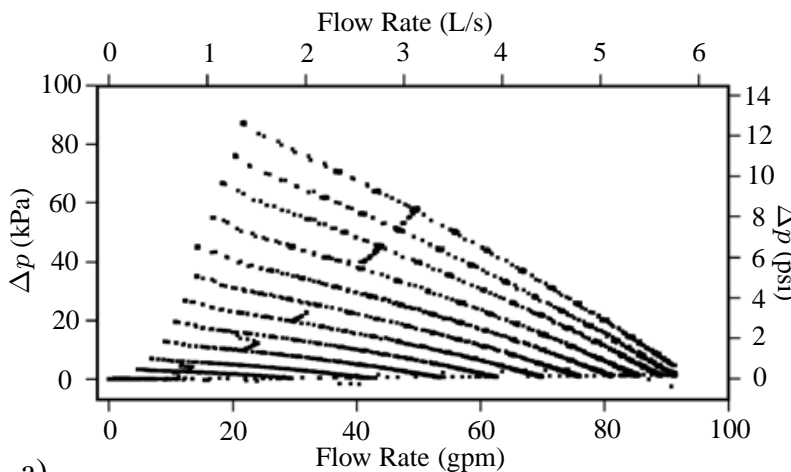

a)

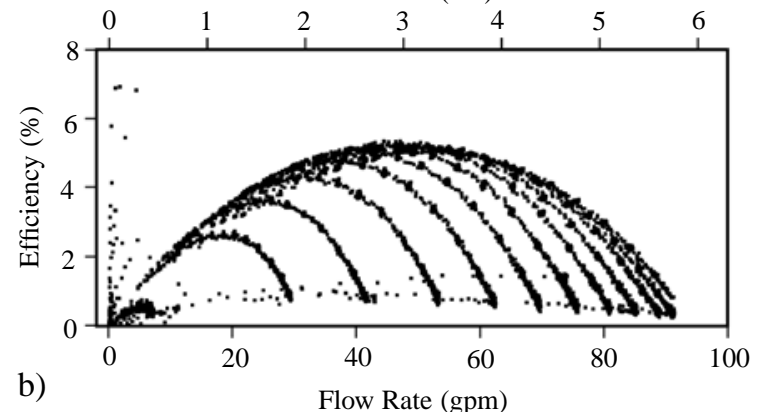

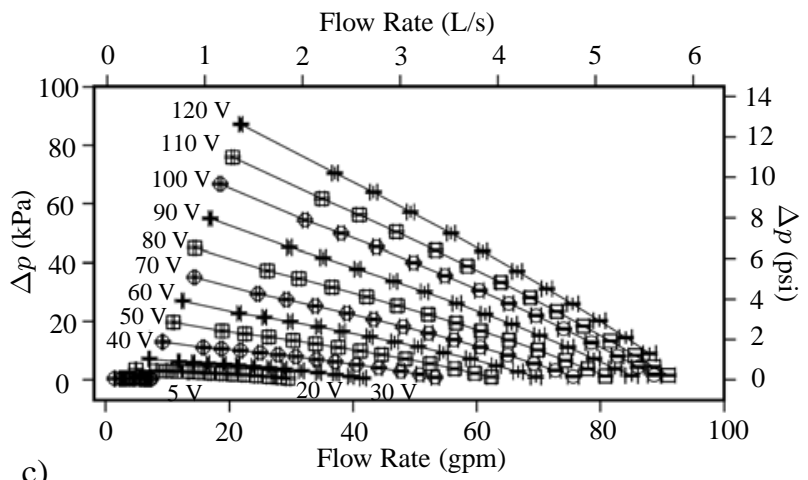

c)

Flow Rate (L/s)

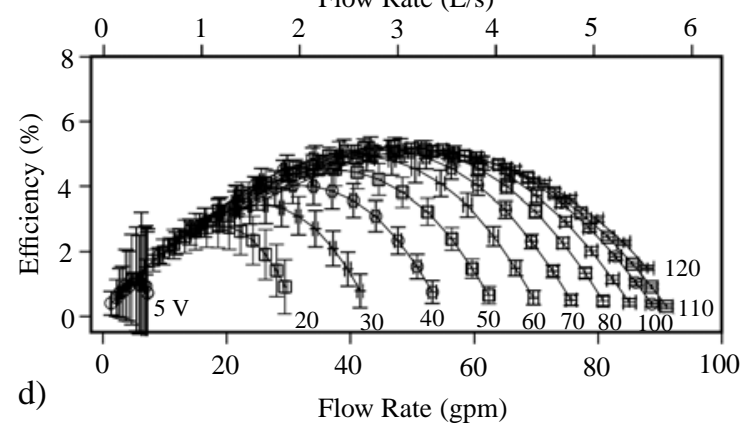

Figure 2. Data from operation at a NaK temperature of $325^{\circ} \mathrm{C}$ and a pump frequency of $36 \mathrm{~Hz}$. All raw data acquired at a sampling rate of $1 \mathrm{~Hz}$, and presented as a) $\Delta p$ and b) efficiency as a function of flowrate. Reduced data presented (with error bars) as c) $\Delta p$ and d) efficiency as a function of flowrate and constant pump voltage.

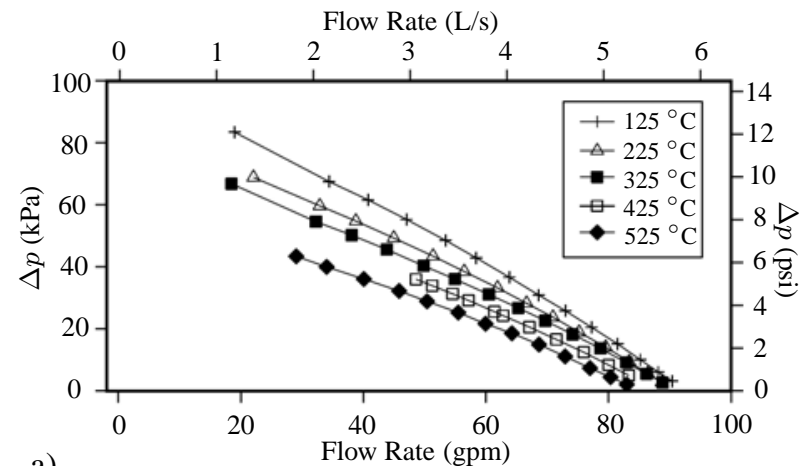

a)

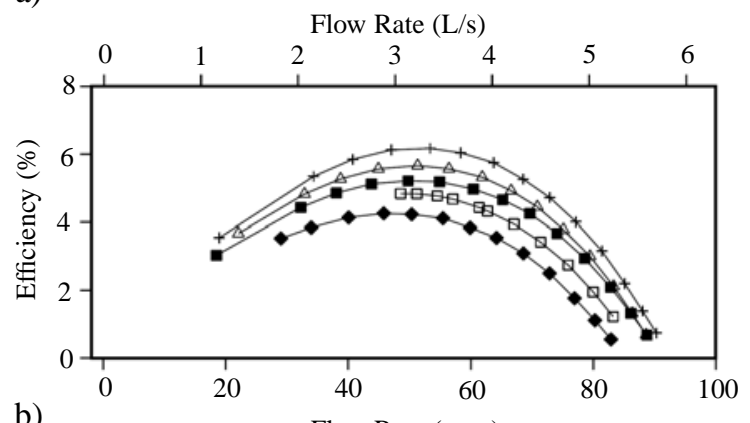

b)

Flow Rate (gpm)

Figure 3. Measured performance curves for pump frequency of $36 \mathrm{~Hz}$ and voltage of $100 \mathrm{~V}$ showing a) $\Delta p$ and b) efficiency as a function of flow rate and $\mathrm{NaK}$ temperature. 
The data presented in Fig. 2a,b were analyzed and are presented as pump performance curves in Fig. 2c,d. The data were analyzed at steady-state flow conditions. Each curve is labeled with the ALIP operating voltage for that particular performance curve. The error on calculated efficiency is given in the standard manner, ${ }^{10}$ assuming no cross correlation between the errors on the three measured parameters. The error bars for the data set are small compared to the magnitude of the measurement. Those on the calculated efficiency are smallest at the highest flow rates and voltages, and grow larger as the flow rate or voltage is reduced.

In Fig. 3, data are presented showing the performance of the pump at NaK temperatures of 125, 225, 325, 425, and $525{ }^{\circ} \mathrm{C}$ for a constant applied voltage of $100 \mathrm{~V}$. The trends in the data show that for a constant voltage, both the $\Delta p$ and the efficiency as a function of flow rate shift lower with increasing temperature.

While constant applied voltage lines are an approximation of constant real power supplied to the pump, they are not, strictly speaking, the same. Consequently, data are plotted in Fig. 4 showing efficiency contours as a function of real power and flow rate at constant temperature. These data exhibit an efficiency island in the middle of the plot and show that the peak of this island becomes smaller as the temperature is increased.
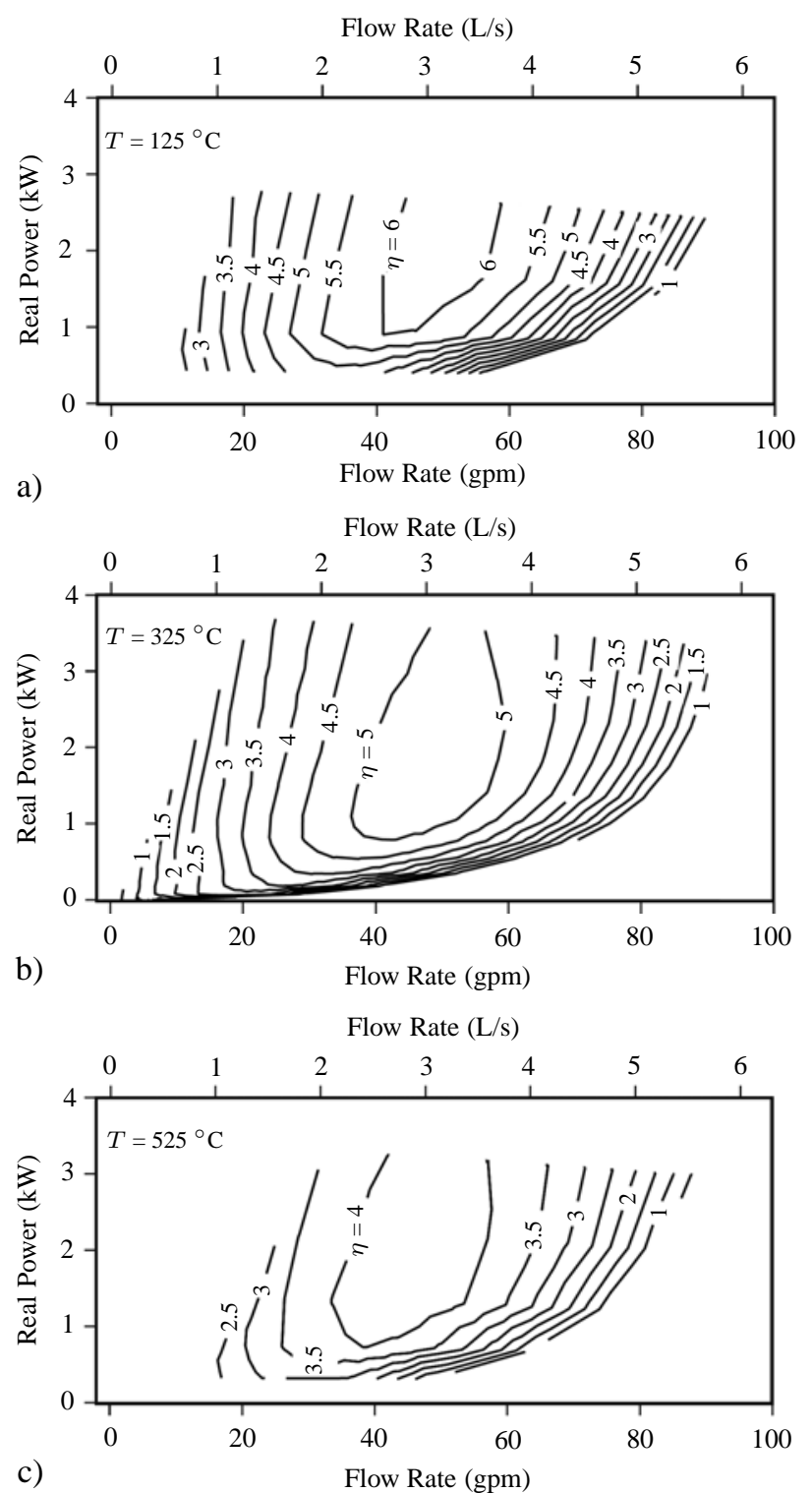

Figure 4. Measured efficiency contour plots from operation at a pump frequency of $36 \mathrm{~Hz}$ as a function of real power to the pump and flow rate for $\mathrm{NaK}$ temperatures of a) $125^{\circ} \mathrm{C}$, b) $325^{\circ} \mathrm{C}$, and c) $525^{\circ} \mathrm{C}$. 

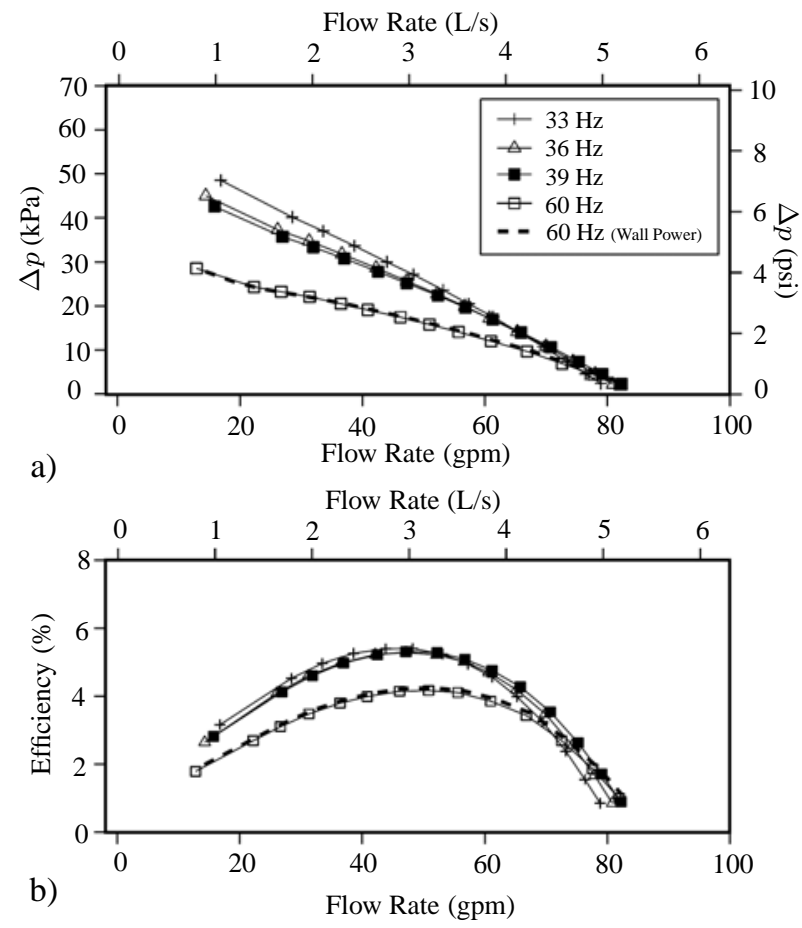

Figure 5. Measured performance curves for operation at a $\mathrm{NaK}$ temperature of $325^{\circ} \mathrm{C}$ and a pump voltage of $80 \mathrm{~V}$ showing a) $\Delta p$ and b) efficiency as a function of flow rate for different displayed pump frequencies. The 'wall power' curve represents operation directly connected to ac-power.

The effects of changing the applied frequency while operating at a constant voltage $(80 \mathrm{~V})$ are explored in Fig. 5. In this figure, the data obtained at 33,36 , and $39 \mathrm{~Hz}$ are similar. The $\Delta p$ levels deviate slightly at lower flow rates, but the efficiency curves as a function of flow rate are fairly consistent across the data set. (Recall the error bars on the measurement as shown in Fig. 2.) As expected, the data obtained while operating at $60 \mathrm{~Hz}$ exhibit significantly lower performance than the other data sets. Of particular interest, however, is the comparison between the data obtained at $60 \mathrm{~Hz}$ with power supplied by the sine wave filtered VFD (open square symbols) and a pure sinusoidal voltage supplied straight from ac wall power. The data set shows that the approximated sinusoidal current supplied by the VFD compares favorably with the ac-supplied power, serving to validate the use of a pulse width modulated source as a method for supplying arbitrary frequency power.

\section{Electromagnetic Field Mapping}

A custom-fabricated, two-axis Hall probe was used to map the time-varying magnetic field inside the ALIP annular flow channel. Figure 6 is a plot of the radial magnetic field component as the phase current varies in time. The magnetic field plots have been accurately scaled to the ALIP drawing shown at the top of the figure, providing full spatial and temporal representation of the field variation throughout the course of one cycle of the phase current. Power was supplied at $60 \mathrm{~Hz}$, and the peak phase current amplitude was approximately $6 \mathrm{~A}$. A right-traveling sinusoidal magnetic field is observed in $B_{r}$, with the local peaks found on the data corresponding to locations where the field is concentrated by the stators. When installed in the ATC, the NaK flow through the pump is right to left (as opposed to the left-toright direction of the traveling wave in the figures), indicating that wires for two of the phases were swapped when performing the field mapping exercise. It was found during testing that the phase current was not equal in all three phases of the pump, which seems to manifest in the difference in peak value of $B_{r}$ at the different locations of the pump during the course of a cycle. 

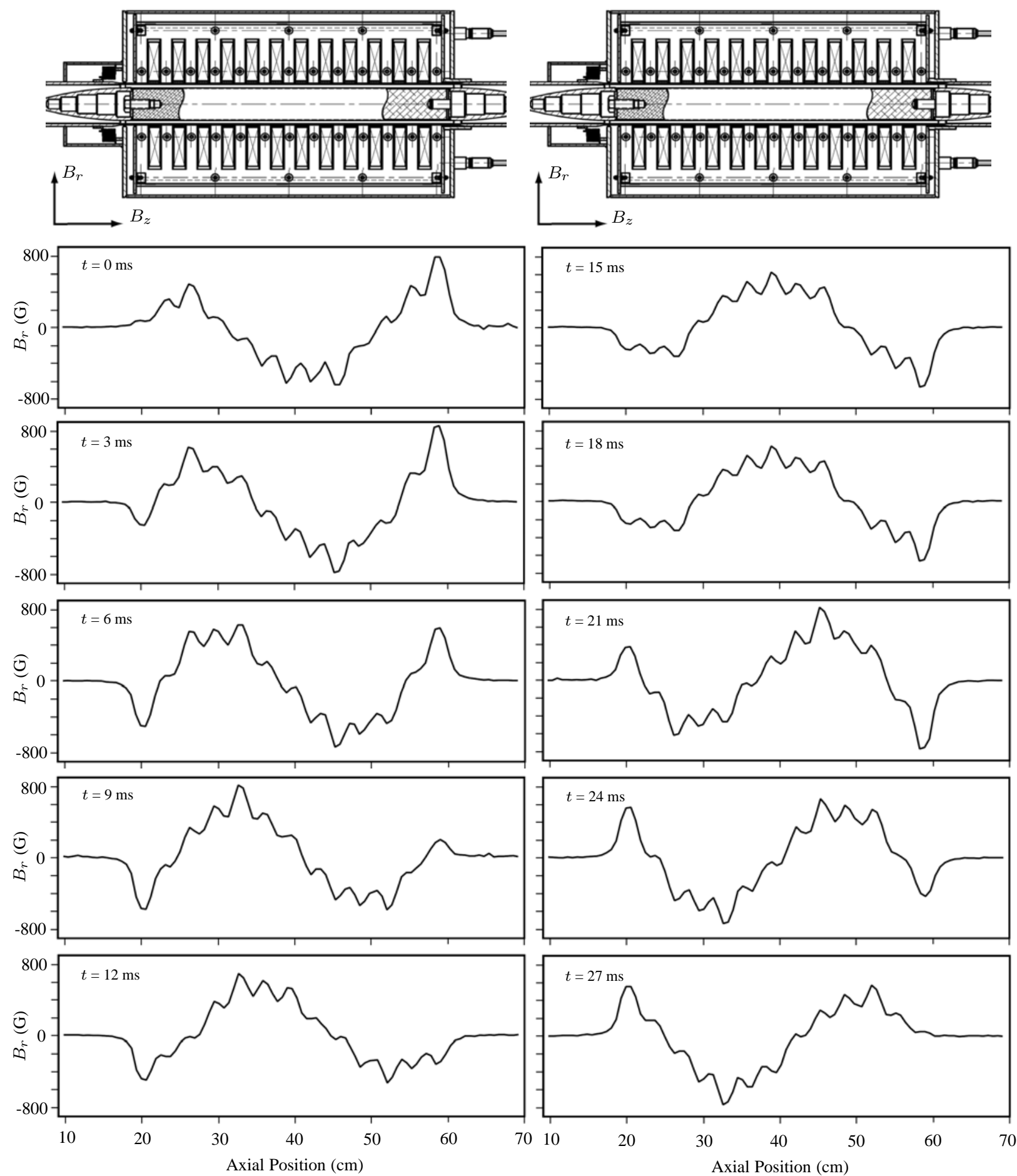

Figure 6. ALIP image (top) on same scale as radial magnetic field $\left(B_{r}\right)$ measurements obtained within the ALIP duct and displayed as a function of axial position for different instances in time. The power was supplied at $60 \mathrm{~Hz}$ with a peak current of approximately $6 \mathrm{~A}$. 


\section{Conclusions}

Testing was performed to quantify the performance of an ALIP. A dedicated test apparatus, the ATC, was fabricated expressly for this purpose. The results of the testing lead to the following conclusions:

- The test setup was well suited to quantifying the performance of the ALIP, allowing for accurate measurement of the various pump input parameters and resulting in narrow, well-defined uncertainties on the data set.

- The VFD output was fed through a sine wave filter and a variac transformer and provided a means to accurately control both the voltage and frequency of the three-phase power applied to the ALIP.

- The flow impedance was successfully controlled using a throttling valve, which allowed for testing across a wide range of flow parameters.

- The pump was tested up to an input of $120 \mathrm{~V}$ over a range of $\mathrm{NaK}$ temperatures from 125 to $525{ }^{\circ} \mathrm{C}$ and at three-phase power frequencies of 33, 36, 39, and $60 \mathrm{~Hz}$. The pump was fed at $60 \mathrm{~Hz}$ using both the VFD and ac power drawn straight from the electrical grid.

- Performance spanned the range of flow rates from roughly 0.16 to $5.7 \mathrm{~L} / \mathrm{s}$ ( 2.5 to $90 \mathrm{gpm}$ ), and $\Delta p$ levels from $<1$ to $90 \mathrm{kPa}(<0.145 \mathrm{psi}$ to roughly $13 \mathrm{psi})$. The maximum efficiency measured during testing was slightly greater than $6 \%$.

- Efficiency decreased as the temperature in the loop increased. Efficiency was maximized near the nominal design point of $36 \mathrm{~Hz}$, and was significantly lower when operating at $60 \mathrm{~Hz}$.

- The data at $60 \mathrm{~Hz}$ exhibited no significant variation in performance between power supplied by the VFD and power drawn directly from the electrical grid.

\section{Acknowledgments}

This work was performed with support of the Fission Surface Power program under NASA's Exploration Technology Development program. We gratefully acknowledge the contributions of Roger Harper, Stanley McDonald, Mark Black, David Bradley, Doug Galloway, and Tommy Reid. We also appreciate the continued Marshall Space Flight Center management support of James Martin, Thomas Brown, Roger Baird, and Thomas Williams. Finally, we extend our thanks to Anita Beatty, whose efforts significantly improved the quality of this publication.

\section{References} 2007.

${ }^{1}$ J. Nainiger, "Affordable Fission Surface Power System Study Final Report," NASA Exploration Systems Mission Directorate Report, Oct.

${ }^{2}$ L.S. Mason, “A Comparison of Fission Surface Power System Options for Lunar and Mars Surface Applications,” NASA/TM-2006-214120, Glenn Research Center, Cleveland, OH, Feb. 2006.

${ }^{3}$ L.S. Mason, "A Practical Approach to Starting Fission Surface Power Development," NASA/TM-2006-214366, Glenn Research Center, Cleveland, OH, July 2006.

${ }^{4}$ L.S. Mason, D. Poston, and L. Qualls, "System Concepts for Affordable Fission Surface Power," NASA/TM-2008-215166, Glenn Research Center, Cleveland, OH, Jan. 2008.

${ }^{5}$ T.J. Godfroy, M. Van Dyke, and R. Dickens, "Realistic Development and testing of Fission Systems at a Non-Nuclear Testing Facility," Space Technologies and Applications International Forum, STAIF-2000, AIP Conf. Proc., Vol. 504, pp. 1208-1210, 2000.

${ }^{6}$ M. Van Dyke, T.J. Godfroy, M. Houts, et al., "Results of a First Generation Least Expensive Approach to Fission Module Tests: Non-Nuclear Testing of a Fission System," Space Technologies and Applications International Forum, STAIF-2000, AIP Conf. Proc., Vol. 504, pp. 1211-1217, 2000

${ }^{7}$ K.A. Polzin, J.B. Pearson, M.P. Schoenfeld, et al., "Performance Testing of a Prototypic Annular Linear Induction Pump for Fission Surface Power," NASA/TP-2010-216430, Marshall Space Flight Center, MSFC, AL, May 2010.

${ }^{8}$ H. Adkins and J.E. Werner, "Analysis of the Fission Surface Power Annular Linear Induction Pump Design Tools Based on Performance Test Results," Idaho National Laboratory Technical Report INL/EXT-10-18211, Idaho Falls, ID, 2010.

${ }^{9}$ B. Walden, "The Two-Meter Wattmeter Method," Technical Documentation, Ohio Semitronics, Inc., Hilliard, OH, 2004.

${ }^{10}$ H.W. Coleman and W.G. Steele, Experimentation and Uncertainty Analysis for Engineers John Wiley and Sons, Inc., New York, 1999. 